\title{
Construct Dimensionality of Personal Energy at Work and Its Relationship with Health, Absenteeism and Productivity
}

\author{
Alexandra F. J. Klijn *, Maria Tims, Evgenia I. Lysova (D) and Svetlana N. Khapova \\ Department of Management and Organisation, School of Business and Economics, Vrije Universiteit, \\ 1081 HV Amsterdam, The Netherlands; m.tims@vu.nl (M.T.); e.lysova@vu.nl (E.I.L.); s.n.khapova@vu.nl (S.N.K.) \\ * Correspondence: afjklijn@gmail.com
}

check for updates

Citation: Klijn, A.F.J.; Tims, M.; Lysova, E.I.; Khapova, S.N. Construct Dimensionality of Personal Energy at Work and Its Relationship with Health, Absenteeism and Productivity. Sustainability 2021, 13, 13132. https://doi.org/10.3390/ su132313132

Academic Editors: Amelia Manuti, Antonino Callea and Maria Luisa Giancaspro

Received: 24 October 2021 Accepted: 22 November 2021 Published: 26 November 2021

Publisher's Note: MDPI stays neutral with regard to jurisdictional claims in published maps and institutional affiliations.

Copyright: (c) 2021 by the authors. Licensee MDPI, Basel, Switzerland. This article is an open access article distributed under the terms and conditions of the Creative Commons Attribution (CC BY) license (https:/ / creativecommons.org/licenses/by/ $4.0 /)$.

\begin{abstract}
Personal energy at work has become a popular topic among HRM scholars and practitioners because it has proven to impact performance. Based on the outcomes of previous research and the call for further exploration of the construct of personal energy at work, we executed this quantitative study. We explored the factor structure of the construct and its relationships with health and productivity by examining the construct that addresses four dimensions: physical, emotional, mental and spiritual energy. Data were collected from 256 employees in an international health tech company and used to analyze construct dimensionality and relationships with health, absenteeism and productivity. The results provided support for the four-dimensional structure of personal energy at work and show that the construct of personal energy at work is related to the outcomes of health, absenteeism and productivity. Implications for theory and practice, as well as directions for future research, are discussed.
\end{abstract}

Keywords: personal energy; sustainable employability; work; productivity; health

\section{Introduction}

Improving employees' personal energy at work has been shown to increase productivity and sustainable employability [1-5] and health [6]. While personal energy is so important, we see that it has not been completely addressed. Due to increasing pressures at work, employees' energy needs to be taken seriously with Human Resource (HR) policies where employee health receives as much or even more concern than productivity [7]. Particularly now, with the current COVID-19 pandemic where many people experience a high workload and work-life balance challenges due to the vague lines between work and private life [8,9], personal energy at work is more crucial than ever.

Personal energy at work is considered to consist of four dimensions: physical, emotional, mental and spiritual energy [10-13]. Although the four dimensions of personal energy have been considered to be important, most of the empirical studies have focused on only one dimension (e.g., Ryan and Frederick [14], two dimensions (e.g., Baker et al. [15] or three dimensions (e.g., Shirom [16]. To our knowledge, a measurement instrument that measures all four dimensions at once is lacking in literature. Meaning that prior research has been limited in examining the full construct of personal energy at work.

The debate on considering all dimensions of a construct is shown in the research of Both-Nwabuwe et al. [17], who identified instruments that measured meaningful work as a multidimensional construct. Both-Nwabuwe et al. [17] were interested in subscale reliability of meaningful work and they suggest that each dimension should be measured by its own reliable subscale. This methodology could be of use for exploring construct dimensionality of personal energy at work.

With regards to work outcomes, prior research did not distinguish between the four different energy dimensions. This can lead to a lesser effective theory and limited practical interventions that derive from these theories. Moreover, an incomplete treatment of personal energy at work can lead to insufficient analyses of factors that drive employees 
feeling energized. For example, a problem could be that HR scholars and practitioners focus on interventions that address physical energy, and fail to address emotional, mental and spiritual energy. Performing interventions like finding purpose in life and meaningful work (spiritual energy) might be equally or even more important to productiveness [18]. The problem is that we don't know the distinct role of each of the dimensions of personal energy at work. With the consequence that HR researchers might be focusing on the wrong drivers and outcomes of personal energy at work.

To address this shortcoming, in this paper we take a multi-dimensional approach to the operationalization and conceptualization of personal energy at work. We examine how personal energy at work is related to outcomes of health, absenteeism and productivity, if so, then how are the distinct dimensions of physical, emotional, mental and spiritual energy individually contributing? The findings could bring solutions for HR researchers and practitioners to identify the factors that lead to a healthier and more productive workplace.

Without understanding how personal energy at work relates to health and productivity, HRM scholars and practitioners will be limited in knowledge needed to measure energy and to develop interventions. In this study-unlike previous studies-we measure all dimensions of personal energy at work, to obtain more clarity on the construct and the outcomes of separate dimensions of personal energy at work. By combining instruments to measure personal energy at work that addresses four dimensions of personal energy at work; physical, emotional, mental and spiritual energy, we build on previous research, with the aim to find evidence for the multidimensional construct of personal energy at work.

Our objective is three-fold, first we aim to operationalize the multidimensionality of personal energy at work (consisting of physical, emotional, mental and spiritual energy). Secondly, we explore the relationship of the overall construct of personal energy at work with health and productivity outcomes. Third, we aim to examine the distinct relationships of physical, emotional, mental and spiritual energy with these health and productivity outcomes.

\section{Theoretical Background}

\subsection{The Four Dimensions of Personal Energy at Work}

Physical, emotional, mental and spiritual energy are the four dimensions of personal energy at work and represent the affective state that makes employees feel confident to do their work [10-13]. The physical energy dimension is driven by straightforward techniques for nutrition, exercise and sleep, as these are the three common variables used in literature concerning physical wellbeing $[6,19,20]$. In addition, feeling physically energized has shown to be related to physical health [4,6,14,20-22].

The emotional energy dimension is about being guided by positive, opportunitybased emotions versus negative emotions, stress management and feeling empathy for colleagues [16,23]. Emotional energy has proved to be related to feeling energized [6,23].

The mental energy dimension emphasizes the cognitive mindset, creativity, focus and staying on course [16,24-26]. The experience of feeling energized at work is linked to a focused and peaceful mind [24-26]. Mental energy like being mindfulness affects contextual performance [27].

Lastly, the spiritual energy dimension is the basis for beliefs, and the role that beliefs play in the actions that people take to shape their lives [28]. It is the source for defining personal core values and purpose in life [29] and searching for meaningful work [30]. Experiencing purpose and meaningful work contributes to feeling energized at work [22,31]. Knowing your personal values and acting on them affects individual performance in the areas of productivity, service quality, and retention [32].

The research on feeling vigorous at work by Shirom [16] relates to personal energy at work, as it contains three dimensions; physical strength, emotional energy, and cognitive liveliness $[16,33]$. The overall construct of vigor has shown to be related to work factors such as job control [34], performance [35] and leader-member exchange [36]. In addition, literature on measurements of the three distinct dimensions of vigor, showed that not all 
dimensions have a significant impact on outcomes. For example, Wefald et al. [35] found a positive relationship between physical and mental energy and job involvement, but no significant relationship was found between emotional energy and job involvement. Armon and Shirom [37] found that physical exercise index was positively associated with the physical strength facet of vigor, but no significance was found between physical exercise and emotional and mental energy. In addition, in the research of Cai et al. [38] showed that emotional energy positively influences the expertise and assumptions that individuals develop, described as tacit knowledge-sharing intention, but physical energy and mental energy were not significantly related to tacit knowledge-sharing intention.

These findings confirm that the different dimensions of personal energy have different relationships and the reason why we need to look at the energy dimensions separately. Therefore, we expect different relationships of each dimension with the outcomes of health, absenteeism and productivity. We will explain our hypothesis for these assumptions next.

\subsection{The Relationship between Personal Energy at Work and Health/Productivity Outcomes}

Next to measurement of sales results, contemporary company measurement tools contain performance management and illness management systems [39] where health and productivity are key indicators for success. Research on health and productivity has shown to provide solid predictions for future company success [40]. Therefore, as energized employees have become the most important asset of a company, the urgency arises about the need for knowledge on how aspects of employees - personal energy dimensions-lead to better health and productivity. When measuring the impact of personal energy at work, health and productivity are perceived as proper work outcomes $[5,6,41]$ as these outcomes indicate performance.

Companies that enhance a vital and energized workforce establish an increase in employees' health [1]. Hrabe et al. [6] found that managing the four energy dimensions has a positive effect on health outcomes. Concluding, personal energy at work is expected to be related to health. That brings us to the following hypothesis.

Hypothesis 1. Personal energy at work is positively related to health.

Productivity is multifaceted, for instance, when an employee is absent due to illness their overall health impacts their productivity. Work productivity loss is therefore often defined as absence from work -absenteeism- plus reduced effectiveness while working -presenteeism- [42]. Concluding, we expect that the overall construct of personal energy at work is related to absenteeism. That brings us to the following hypothesis.

Hypothesis 2. Personal energy at work is negatively related to absenteeism.

Energized employees can be considered a crucial aspect of sustainable employability at work [1]. Feeling energized at work is essential for a productive workplace [4]. Suggesting that when employees feel more energized at work, their productivity improves. That brings us to the following hypothesis.

\section{Hypothesis 3. Personal energy at work is positively related to productivity.}

When we look at the impact of the overall construct of personal energy at work, we need to find out how the four energy dimensions are contributing. The dimensions might be equally important for the outcomes, they can strengthen each other or even diminish each other. As mentioned earlier, previous research as shown that the impact of the energy dimensions can diver $[35,37,38]$. One energy dimension might be contributing more to specific work outcomes than other dimensions. For example, physical energy might be of more importance to feeling healthy than spiritual energy. As people who experience high spiritual energy, like a strong sense of calling, are likely to see their work as a moral duty and they may sacrifice personal quality time and comfortable work [43]. 
We conclude that it is difficult to compose a hypothesis on the different relationships of each dimensions, therefore we performed exploratory research. To identify the possible relationships between the energy dimensions and health, absenteeism and productivity, we posit the following our explorative research question:

RQ. To what extent are the dimensions of personal energy at work distinguishably related to health, absenteeism and productivity?

\section{Materials \& Methods}

\subsection{Sample and Procedure}

We collected the data in a multinational health tech company. The survey was sent to employees who were going to participate in energy management training in The Netherland, US and China. The one-day classroom training focused on energy management through a comprehensive examination of goals in relation to one's personal energy, where participants learn how to better manage their energy through simple techniques such as exercise, recovery and nutrition management. People could apply for the training voluntarily. Over the course of four months, all 275 employees who participated in the energy management training were invited to fill in the survey prior to the training. Participants were free to fill in the online questionnaire at work or at home. Filling out the survey was voluntary, however, it was strongly recommended by stressing that it gives participants insights into their current energy levels, which could be of use before entering the training. The survey was set up as a pre-test and post-test to measure the effect of the intervention. However, the data we collected in the post-test had an insufficient number of responses. Therefore, we could only analyze the data from the pre-test.

Employees had jobs in marketing, product engineering, finance, legal and communications. Employees could fill in the survey from two weeks before the start of their training until the beginning of the training. Participants received an email with a link to the survey. The HR department and line managers sent emails and invited employees face to face to participate. There was one link to the questionnaire, therefore no unique login codes were used. In addition, participants were informed that the survey results were reported in an aggregated format in a manner that will not be tied to an employee. The participants received their personal survey outcomes prior to the energy management training.

In total, 256 employees (93\% response) filled in the survey. Employees were working in the United States $(N=80)$, China $(N=18)$ and The Netherlands $(N=156)$. Of the participants, $53.1 \%$ were female. In this study, $25.0 \%$ of the participants had a managerial position and almost everyone had at least a Bachelor's degree (95\%). The average age of the participants was 38.3 years $(\mathrm{SD}=9.2)$. Participants worked on average $45.6(\mathrm{SD}=8.5)$ hours a week and on average $6.2(\mathrm{SD}=6.5)$ years for their current employer. Total years of work experience were, on average, $14.9(\mathrm{SD}=9.7)$ years.

\subsection{Measures}

The vigor construct developed by Shirom et al. [16] has a large overlap with personal energy at work. Vigor, described as the affective state of energy reservoirs that employees possess, is the response to elements in their job and work environment and contains three dimensions; physical strength, emotional energy, and cognitive liveliness [16,33]. We consider these the dimensions of vigor to represent the dimensions of physical, emotional and mental energy. The spiritual dimension is lacking in the vigor construct. Walker et al. [44] measured spiritual growth, a facet we consider to be representative for spiritual energy because these items reflect the core of the spiritual energy at work: finding purpose and meaning in life. Therefore, we use the following measurements to assess the four energy dimensions.

Personal energy at work was measured by using separate instruments to cover all four dimensions. All questions were phrased in the context of work. The physical, emotional and mental dimensions of energy were measured with the Shirom-Melamed Vigor Measure 
(SMVM) scale [16]. This fourteen-item scale was assessed on a five-point Likert scale ( $1=$ never and $5=$ every time). Physical energy was measured with five items $(\alpha=0.89)$, an example item is 'I feel I have physical strength'. Emotional energy was measured with four items $(\alpha=0.80)$, an example item is 'I feel able to show warmth to others'. Mental energy was measured with five items $(\alpha=0.80)$, an example item is 'I feel mentally alert'. Spiritual energy was measured with three items of the Health Promoting Lifestyle Profile (HPLP II) regarding spiritual growth [44]. An example item is 'I work toward long-term goals in my life' which could be answered using a four-point Likert scale ( 1 = never and 4 = routinely) $(\alpha=0.71)$.

Many studies that measure self-reported health, productivity or performance use one or two questions [4,21,45-48]. These questions, often copied from the ASSET (An Organizational Stress Screening Tool), address how many days employees have been absent/present during a period and a question about how productive the respondent has felt in the job $[46,49,50]$. Overall health is often measured with one question: how would you rate your overall health [49]. Therefore, we choose the following measurements for our outcomes.

Overall health was measured with the one-item health measure, derived from the Organizational Stress Screening Tool (ASSET) from Faragher et al. [49]: 'Over the last 3 months, how would you rate your overall health?' Answers were noted on a slider step scale from 1 (poor) to 10 (good).

Absenteeism was measured with the one item absenteeism measure, derived from the ASSET from Faragher et al. [49]: 'Over the last 3 months, how many working days have you been off work through illness or injury?' This was an open question where people could enter a number.

Productivity was measured with the one item productiveness measure, derived from the ASSET from Faragher et al. [49]: 'Over the last 3 months, roughly how productive have you felt in your job?' Answers were noted on a slider step scale from 0 to $100 \%$. The full questionnaire can be found in Appendix A (Table A1).

\subsection{Analysis Strategy}

We used SPSS AMOS 27 to perform confirmatory factor analysis (CFA) [51] to examine the factor structure of personal energy at work. To test our hypotheses, we used AMOS to perform structural equation modeling (SEM) with maximum likelihood. We first examined whether the four dimensions of personal energy fit the overall construct of personal energy. We performed a second-order confirmatory factor analysis for personal energy at work to test construct dimensionality. The model contained the four dimensions of personal energy as latent factors (i.e., physical, emotional, mental and spiritual) with their respective items as indicators. Then we measured the relationship of the overall construct of personal energy at work with the outcomes of health, absenteeism and productivity. Finally, we created a path model to explore the distinct relationship of physical, emotional, mental and spiritual energy to the outcomes.

In addition to the statistic of the chi-square goodness of fit $\left(\chi^{2}\right)$, the analyses assessed the degrees of freedom (DF), the $p$-value, the comparative fit index (CFI), the root mean square error of approximation (RMSEA) and the Normed Fit Index (NFI). The conventional cut-off values of these fit indices were used to assess the model fit (i.e., $p<0.05, \mathrm{CFI} \geq 0.90$, NFI $\geq 0.90$, and RMSEA $0.05<0.10$ ).

\section{Results}

\subsection{Confirmatory Factor Analyses}

All factor loadings ranged between 0.54 and 0.97 and the variables had a distribution close to normal distribution. In addition, in all models, adequate values were found for the chi-square goodness of fit $\left(\chi^{2}\right)$, the degrees of freedom (DF), the $p$-value, the comparative fit index (CFI) and the root mean square error of approximation (RMSEA). For Normed Fit Index (NFI), acceptable values were found. 
The first order CFA factor loadings of the four energy dimensions showed a good fit $\left(\chi^{2}=219.73, \mathrm{df}=113, \mathrm{CFI}=0.94, \mathrm{NFI}=0.89, \mathrm{RMSEA}=0.06\right)$. The second-order CFA results support the four-dimensional construct of personal energy at work. Personal energy at work, with four factors: physical, emotional, mental and spiritual dimensions, showed a good second-order model fit $\left(\chi^{2}=222.28, \mathrm{df}=115, \mathrm{CFI}=0.94, \mathrm{NFI}=0.89\right.$, RMSEA $\left.=0.06\right)$. This means that the four energy dimensions can been seen as one construct, personal energy at work.

\subsection{Descriptives}

Table 1 presents the means, standard deviations, correlations and reliability scores for the studied variables. As can be seen from the table, all energy dimensions are correlated to each other, ranging between $r=0.22$ and $r=0.72, p<0.01$. Furthermore, all energy dimensions are correlated with all outcomes, with the exception of spiritual energy, which is not correlated with absenteeism.

Table 1. Means, standard deviations, correlations and reliability for all variables.

\begin{tabular}{|c|c|c|c|c|c|c|c|c|c|c|c|c|}
\hline & Variable & $\mathbf{M}$ & SD & 1 & 2 & 3 & 4 & 5 & 6 & 7 & 8 & 9 \\
\hline 1 & Age & 38.26 & 9.23 & - & & & & & & & & \\
\hline 2 & Gender & 1.54 & 0.50 & $-0.20^{* *}$ & - & & & & & & & \\
\hline 3 & $\begin{array}{l}\text { Physical } \\
\text { energy }\end{array}$ & 3.41 & 0.61 & 0.13 * & -0.07 & $(0.89)$ & & & & & & \\
\hline 4 & $\begin{array}{l}\text { Emotional } \\
\text { energy }\end{array}$ & 3.87 & 0.53 & 0.09 & $0.16^{*}$ & $0.34^{* *}$ & $(0.80)$ & & & & & \\
\hline 5 & $\begin{array}{l}\text { Mental } \\
\text { energy }\end{array}$ & 3.49 & 0.50 & 0.09 & -0.02 & $0.72^{* *}$ & $0.40^{* *}$ & $(0.80)$ & & & & \\
\hline 6 & $\begin{array}{l}\text { Spiritual } \\
\text { energy }\end{array}$ & 2.96 & 0.62 & 0.08 & 0.04 & $0.31^{* *}$ & $0.22 * *$ & $0.31^{* *}$ & $(0.71)$ & & & \\
\hline 7 & Health & 2.52 & 0.62 & 0.10 & -0.10 & $0.54^{* *}$ & 0.14 * & $0.43 * *$ & $0.21^{* *}$ & - & & \\
\hline 8 & Absenteeism & 7.29 & 1.61 & 0.03 & 0.04 & $-0.22 * *$ & $-0.16^{*}$ & $-0.31^{* *}$ & -0.06 & $-0.31^{* *}$ & - & \\
\hline 9 & Productivity & 2.05 & 8.93 & -0.00 & 0.07 & $0.47^{* *}$ & $0.18^{* *}$ & $0.46^{* *}$ & $0.15^{*}$ & $0.49^{* *}$ & $-0.35^{* *}$ & - \\
\hline
\end{tabular}

${ }^{* *}$ Correlation is significant at the 0.01 level (2-tailed). ${ }^{*}$ Correlation is significant at the 0.05 level (2-tailed).

\subsection{Hypothesis Testing}

To test the hypotheses, we modeled personal energy at work as a second-order factor and the outcomes as manifest variables (see Figure 1). The model fits the data well $\left(\chi^{2}=306.96, \mathrm{df}=163, \mathrm{CFI}=0.93, \mathrm{NFI}=0.87, \mathrm{RMSEA}=0.06\right)$. The hypotheses stated that the construct of personal energy at work is related to the outcomes of health, absenteeism and productivity. The findings showed that personal energy at work showed a positive relationship with health $(\gamma=0.55, p<0.01)$, thus $\mathrm{H} 1$ is supported. Personal energy at work showed a negative relationship with absenteeism $(\gamma=-0.30, p<0.01)$, supporting H2. Furthermore, H3 was supported as personal energy at work showed a positive relationship with productivity $(\gamma=0.55, p<0.01)$.

These results, compared to the correlations, suggest that all energy dimensions are important for personal energy at work; however this does not imply that all energy dimensions are equally contributing. Therefore, we investigated the distinctiveness of the dimensions of personal energy at work in another SEM model in AMOS where the energy dimensions were modeled as latent variables with their items as indicators, and the outcomes were placed in one model. This model showed an adequate model fit $\left(\chi^{2}=284.98\right.$, $\mathrm{df}=152, \mathrm{CFI}=0.94, \mathrm{NFI}=0.88, \mathrm{RMSEA}=0.06)$. We found two significant relationships: physical energy was positively related to health $(\gamma=0.53, p<0.01)$ and mental energy was negatively related to absenteeism $(\gamma=0.55, p<0.01)$. All other relationships between energy dimensions and outcomes were not significant. The trimmed SEM model is shown in Figure 2. 


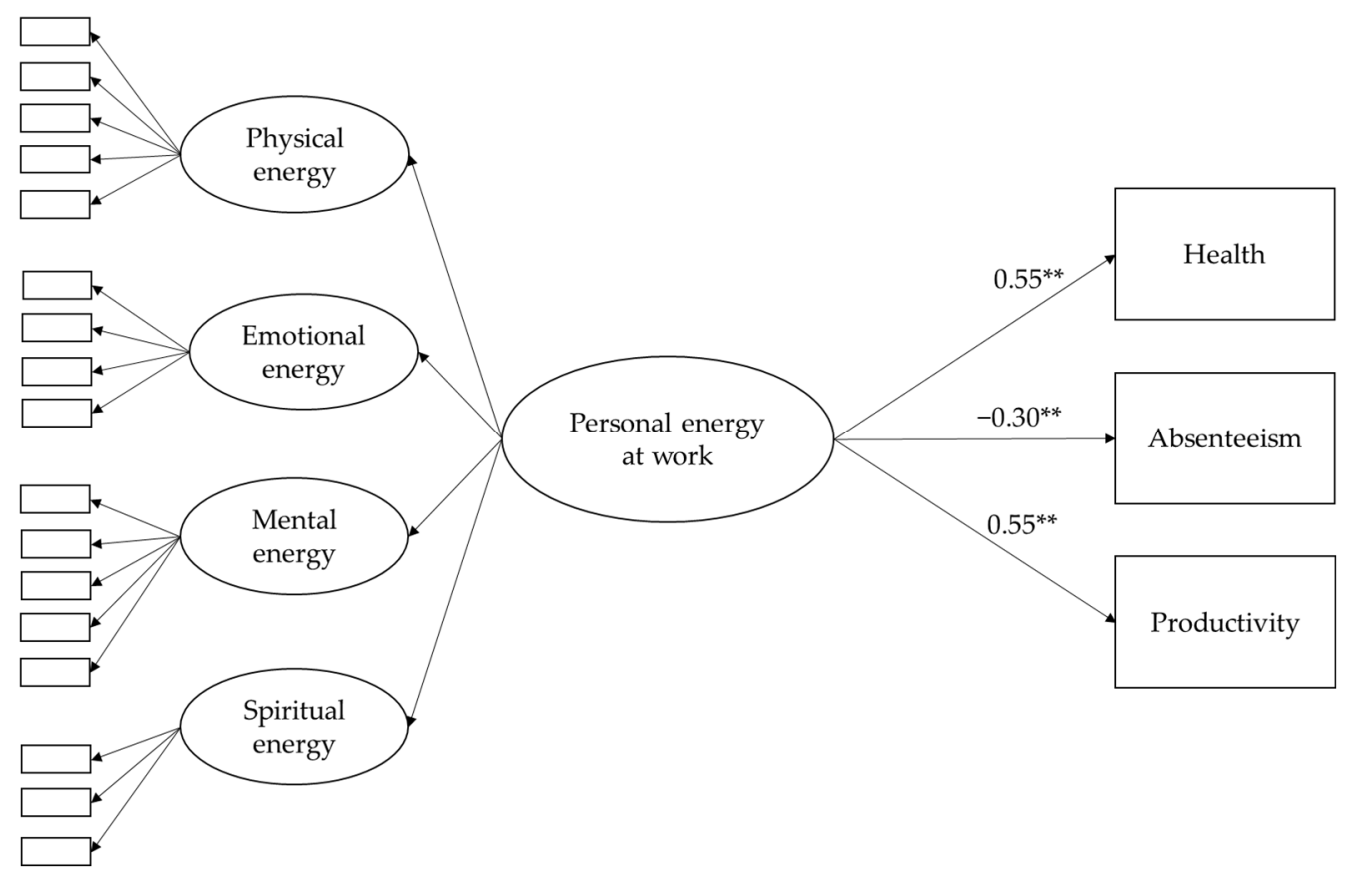

Figure 1. SEM model of total construct of personal energy at work and the relationship with health, absenteeism and productivity. ${ }^{* *} p<0.001$.

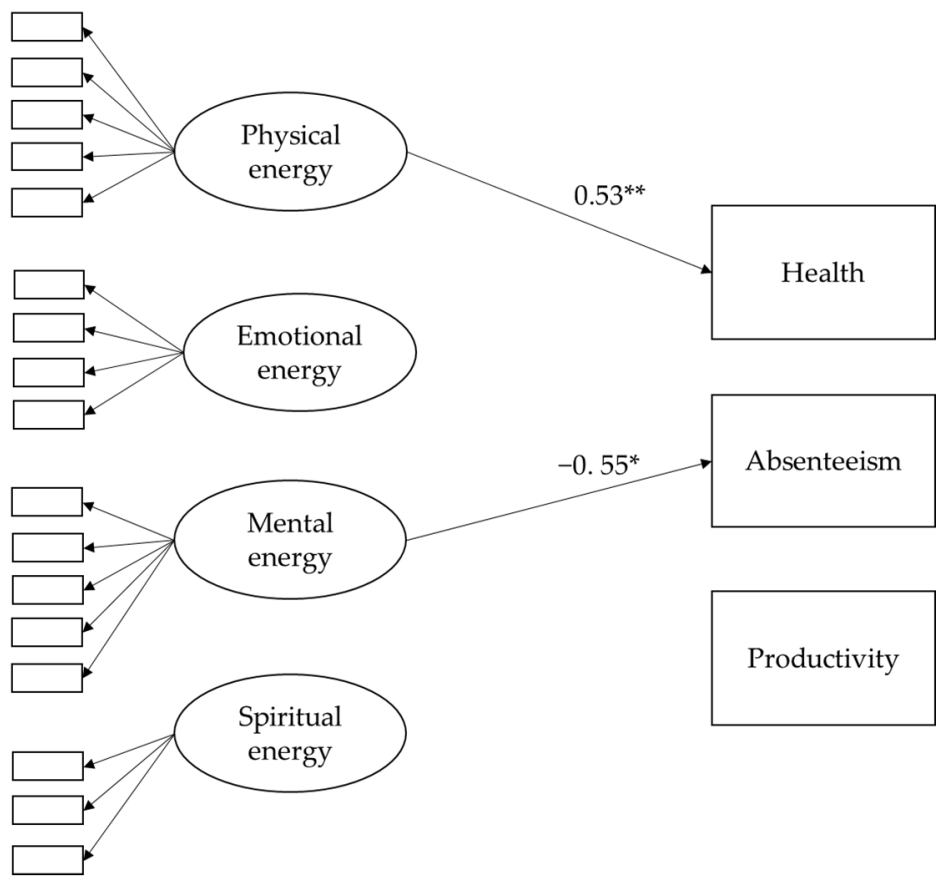

Figure 2. Trimmed SEM model of personal energy dimensions and the relationship with health, absenteeism and productivity. ${ }^{* *} p<0.001,{ }^{*} p<0.05$.

We compared the fit of the two models based on the one-tailed probability value for a chi-square test, given the chi-square and degrees of freedom ratio $\left(\Delta x^{2} / \Delta \mathrm{df}\right)$. We found a significant difference between the models $(p=0.02)$. As the model with the energy dimensions as latent variables, with their items as indicators (Figure 2), had the lower chi-square and degrees of freedom values, we conclude that this model has the best fit with the data. 


\section{Conclusions and Discussion}

In this article, we argued that a better understanding of the construct of personal energy at work, is needed for HR researchers and practitioners to improve work outcomes. We examined its factor structure and we hypothesized that personal energy at work is positively related to health and productivity, and negatively related to absenteeism. The results of our study were consistent with the hypotheses.

The study findings supported previous theories [10-13], that personal energy at work consist out of for dimensions: physical, emotional, mental and spiritual energy. Meaning that physical, emotional, mental and spiritual energy contribute to the overall construct of personal energy at work, in the way that personal energy at work is a reflective construct.

The construct of personal energy at work, has shown to be positively related to health and productivity, and negatively related to absenteeism. The CFA showed that the impact of personal energy at work can be measured as an overall construct. When we look at personal energy as one construct, we see relationships with all three outcomes: health, absenteeism and productivity (Figure 1). These results underline previous research on feeling energized and the relationships with health [6] and productivity $[1,5,41]$.

In addition, we examined the distinct role of each of the energy dimension within the construct of personal energy at work, in relation to the outcomes. We found that the relationships with the outcomes of health, absenteeism and productivity differs between the overall construct of personal energy at work, versus the distinct energy dimensions. Physical energy was significantly related to health. This is in line with previous research like Ellingson et al. [20] and Prasad et al. [21]. Mental energy was significantly related to absenteeism, underling the findings Good et al. [52].

Emotional and spiritual energy did not show a significant relationship with any outcome. This was unexpected as previous research has show that emotional energy and spiritual energy are related to health and productivity $[6,53]$. A possible reasoning for why the spiritual and emotional dimensions did not have significant relationships with the outcomes could be that people are willing to sacrifice elements of their wellbeing because they deprioritize it compared to the causes their work serves [43].

\subsection{The Theoretical Contributions}

With this paper we contribute to the existing literature on the dimensions of personal energy at work [10-12] and the evidence on feeling vigorous at work [16]. Although prior studies mentioned four dimensions of personal energy $[10,11,54]$ the measurement of the distinct four energy dimensions was lacking in literature. We have empirically showed the value of having energy as a multidimensional phenomenon.

The construct of vigor, as explained by Shirom [16], contains three similar dimensions as personal energy at work, physical, emotional and mental energy. The three factor structure of vigor was confirmed by other scholars [35,55]. We added spiritual items from the Health Promoting Lifestyle Profile (HPLP II) [44] to the questionnaire of vigor [16]. The secondorder factor analysis for the four dimensions personal energy at work, fits the data well, meaning that personal energy at work can be perceived as a four-dimensional construct.

When we measure personal energy at work as one construct, without looking at the separate relationship of each dimension, we might be less able to draw conclusions or know less well what we can do for employees, like interventions to increase personal energy. Therefore, we examined both the whole construct of personal energy at work, as well as the different dimensions, in relation to health, absenteeism and productivity.

Physical energy and mental energy had a high correlation. This might indicate that physical energy and mental energy represent similar aspects. However, they are differently related to the outcomes, meaning that they are different facets of personal energy at work.

Because the overall construct has a strong and significant relationship with productivity, versus no significant relationship with the individual dimensions, we conclude that the energy dimensions strengthen each other in the relationship with productivity. The relationship between the construct of personal energy at work with health is slightly stronger when 
all energy dimensions are combined, this suggests that the energy dimensions strengthen each other in the relationship to health. The relationship between the construct and absenteeism becomes less strong when all dimensions are combined, suggesting that the dimensions might diminish each other in the relationship to absenteeism. However, we also found strong correlations between absenteeism and physical, emotional and mental energy, only spiritual energy did not correlate with absenteeism. Further research on drivers for absenteeism is needed to explain these findings.

Concluding, the results show that the four dimensions of personal energy at work have a distinguishable relationship with health, absenteeism and productivity. Therefore, this paper adds evidence to the theoretical variance of the construct of personal energy at work. In addition, it contributes to existing literature on the distinctness of different energy dimensions, as found in research on vigor [35,37,38].

Now that we have identified the distinct role of each energy dimension, HR researchers can enhance their knowledge and research to predict the impact of energized employees on critical outcomes such as productivity. The findings of this study will help HR researchers with further investigation of improving personal energy theories, like the theory of feeling vigorous Shirom [16].

\subsection{Limitation and Recommendations for Future Research}

The present study has several limitations. Although the design allowed us to measure dimensions of personal energy at work in relation to health and productivity outcomes, other circumstances were not controlled for and may have influenced the results. For example, we did not take into account, the time of day, time of week or even season that participant answered questions about their energy. In addition, the fact that this is selfreported data may also be a limitation. Having colleagues and line manager participate can might bring more accurate results.

Unfortunately, there was not enough data on post-intervention sessions which precluded the examination of the relationships over time. Therefore, a longitudinal or twowave study can provide more clarity on the relationships by also examining whether feeling healthy and productive can make people feel more energized. Or there might be a feedback loop where the relationships are reciprocal. It would be valuable to see a follow-up study that randomly assigns different conditions to different levels of feeling energized to better examine the effect on outcomes such as health and productivity. Interesting follow up could be to test if the personal energy dimensions can act as a mediator between a healthy lifestyle and work outcomes.

Although we used outcomes measures as used in previous validated research, a limitation is that they are one-item measures. The disadvantages of using one-item measures is low content validity, as it is difficult to capture the construct with one item. One item measures have fewer points of discrimination (sensitivity) and they miss a measure of internal-consistency reliability.

Another limitation might be that the group is quite homogeneous; highly educated employees within a health tech company who voluntarily filled in a survey that was part of a voluntarily energy management intervention. Recommendation for further research could be to test the questionnaire for a larger, more heterogeneous audience and repeat the survey after a specific time.

As the survey was distributed the United States, China and The Netherlands, we must take into account the cultural context. For example, the openness about health and productivity might be different based on cultural backgrounds. A possible limitation might be that the cultural context influences the self-reported output and therefore the relationships between the independent variables and the dependent variables could differ per country.

Further research on spiritual survey items is needed. In this case the items mainly address having purpose. Items that relate to other aspects of the spiritual dimension, like having meaningful work and core values, might provide valuable information. For 
example, research on the relationship between experiencing a purposeful life, meaningful work, and being more productive, could provide important knowledge for future research.

\subsection{Practical Implication}

Having energized employees is key for sustainable performance at work [1]. Therefore, knowing how the dimensions of personal energy at work are related to outcomes such as productivity, is important for HR practitioners when developing employee engagement survey's and personal development workshops. A contribution of this paper is that it investigates the distinct impact of physical, emotional, mental and spiritual energy in relation to health absenteeism and productivity. This can benefit HR practitioners in improving business outcomes by knowing what drives health and productivity outcomes.

By adding the measurement items of spiritual growth to the items that measure vigor, we established a questionnaire that measures the complete construct of personal energy at work. In addressing not only physical, emotional and mental energy but also including the spiritual dimension as a key dimension to the construct of personal energy at work, HR practitioners can use this measurement tool do enhance their interventions to gain more knowledge on how to improve personal energy at work.

The findings show that the dimensions of personal energy at work are contributing to health, absenteeism and productivity. This gives HR practitioners more tools to develop strategies to increase productivity. It helps practitioners to focus more on certain energy dimensions that yield distinct results. Overall, this paper contributes to the implementation of HR policies in a way that better weighted decisions can be taken when setting HR goals to achieve an energized workplace.

Author Contributions: Data curation, A.F.J.K.; Formal analysis, A.F.J.K.; Funding acquisition, A.F.J.K.; Investigation, A.F.J.K.; Methodology, A.F.J.K.; Project administration, A.F.J.K.; Resources, A.F.J.K.; Software, A.F.J.K.; Supervision, M.T., E.I.L. and S.N.K.; Validation, A.F.J.K., M.T., E.I.L. and S.N.K.; Visualization, A.F.J.K.; Writing-original draft, A.F.J.K. All authors have read and agreed to the published version of the manuscript.

Funding: This research received no external funding.

Institutional Review Board Statement: Based on the submitted information in the online selfcheck, the Research Ethical Review Board declares that the research proposal entitled 'Construct Dimensionality of Personal Energy at Work and its Relationship with Health, Absenteeism and Productivity' complies with the ethical guidelines of the School of Business and Economics, Vrije Universiteit Amsterdam. The reference number is SBE11/24/2021akn442.

Informed Consent Statement: By participating in the survey it was explained that participants give a consent that meets the following criteria: a. Information provided in clear language for the target audience. $\mathrm{b}$. Information about the nature, content, procedures and risks of the study will be sufficient to let. c. the subject consider his/her consent adequately. d. The purposes of data collection and use clearly described. e. Consent includes a statement that identifiable personal information of the subject will not be. f. passed to a third party without consent. g. Consent will be given voluntarily. h. Subjects will be entitled to refuse or withdraw from participation without negative consequences. i. for them. j. Contact details of the researcher(s) provided.

Data Availability Statement: The data are not publicly available due to privacy reasons.

Conflicts of Interest: The authors declare no conflict of interest.

\section{Appendix A}

Table A1. Survey items. Items reprinted from existing measures, sources: [16,46,51].

\begin{tabular}{cc}
\hline Variable. & Question \\
\hline Energy Physical & A feeling of vitality \\
Energy Physical & I feel I have physical strength \\
Energy Physical & I feel energetic \\
Energy Physical & I feel full of pep (energy, vigor, liveliness, spirit) \\
\hline
\end{tabular}


Table A1. Cont.

\begin{tabular}{|c|c|}
\hline Variable. & Question \\
\hline Energy Physical & I feel vigorous (strong, healthy, full of energy) \\
\hline Energy Emotional & I feel capable of being sympathetic to coworkers and customers \\
\hline Energy Emotional & I feel I am capable of investing emotionally in coworkers and customers \\
\hline Energy Emotional & I feel able to show warmth to others \\
\hline Energy Emotional & I feel able to be sensitive to the needs of coworkers and customers \\
\hline Energy Mental & $\begin{array}{l}\text { A feeling of flow (the mental state of fully immersed in a feeling of energized } \\
\text { focus, full involvement, and enjoyment in the process of the activity) }\end{array}$ \\
\hline Energy Mental & I feel mentally alert \\
\hline Energy Mental & I feel able to be creative \\
\hline Energy Mental & I feel I can think rapidly \\
\hline Energy Mental & I feel I am able to contribute new ideas \\
\hline Energy Spiritual & I believe that my life has purpose \\
\hline Energy Spiritual & I work toward long-term goals in my life \\
\hline Energy Spiritual & I am aware of what is important to me in life \\
\hline Productivity & Over the last 3 months, roughly how productive have you felt in your job? \\
\hline Health & Over the last 3 months, how would you rate your overall health? \\
\hline Absenteeism & $\begin{array}{c}\text { Over the last } 3 \text { months, how many working days have you been off work } \\
\text { through illness or injury? }\end{array}$ \\
\hline Descriptives & What is your age? \\
\hline Descriptives & What is your gender? \\
\hline Descriptives & What country do you work in? \\
\hline Descriptives & What is the highest level of education you have completed? \\
\hline Descriptives & How many hours a week do you work on average? \\
\hline Descriptives & For how many years have you been employed within Philips? \\
\hline Descriptives & $\begin{array}{l}\text { For how many years have you been employed in total (all work employers } \\
\text { together)? }\end{array}$ \\
\hline Descriptives & Do you have a managerial position (direct reports)? \\
\hline
\end{tabular}

\section{References}

1. de Jonge, J.; Peeters, M. The Vital Worker: Towards Sustainable Performance at Work. IJERPH 2019, 16, 910. [CrossRef]

2. Niessen, C.; Maeder, I.; Stride, C.; Jimmieson, N.L. Thriving When Exhausted: The Role of Perceived Transformational Leadership. J. Vocat. Behav. 2017, 103, 41-51. [CrossRef]

3. Spreitzer, G.; Porath, C. Creating Sustainable Performance. Harv. Bus. Rev. 2012, 9, 1-9.

4. van Scheppingen, A.R.; de Vroome, E.M.M.; ten Have, K.C.J.M.; Zwetsloot, G.I.J.M.; Bos, E.H.; van Mechelen, W. Motivations for Health and Their Associations With Lifestyle, Work Style, Health, Vitality, and Employee Productivity. J. Occup. Environ. Med. 2014, 56, 540. [CrossRef]

5. Abid, G.; Ijaz, S.; Butt, T.; Farooqi, S.; Rehmat, M. Impact of Perceived Internal Respect on Flourishing: A Sequential Mediation of Organizational Identification and Energy. Cogent Bus. Manag. 2018, 5, 1507276. [CrossRef]

6. Hrabe, D.P.; Melnyk, B.M.; Buck, J.; Sinnott, L.T. Effects of the Nurse Athlete Program on the Healthy Lifestyle Behaviors, Physical Health, and Mental Well-Being of New Graduate Nurses. Nurs. Adm. Q. 2017, 41, 353-359. [CrossRef]

7. Guest, D.E. Human Resource Management and Employee Well-Being: Towards a New Analytic Framework. Hum. Resour. Manag. J. 2017, 27, 22-38. [CrossRef]

8. Schieman, S.; Badawy, P.J.; Milkie, M.A.; Bierman, A. Work-Life Conflict During the COVID-19 Pandemic. Socius 2021, 7, 2378023120982856. [CrossRef]

9. Xiao, Y.; Becerik-Gerber, B.; Lucas, G.; Roll, S.C. Impacts of Working From Home During COVID-19 Pandemic on Physical and Mental Well-Being of Office Workstation Users. J. Occup. Environ. Med 2021, 63, 181-190. [CrossRef]

10. Fritz, C.; Lam, C.F.; Spreitzer, G.M. It's the Little Things That Matter: An Examination of Knowledge Workers' Energy Management. Acad. Manag. Perspect. 2011, 26, 28-39.

11. Pluta, A.; Rudawska, A. Holistic Approach to Human Resources and Organizational Acceleration. J. OrgChange Mgmt 2016, 29, 293-309. [CrossRef]

12. Quinn, R.W.; Spreitzer, G.M.; Lam, C.F. Building a Sustainable Model of Human Energy in Organizations: Exploring the Critical Role of Resources. Acad. Manag. Ann. 2012, 6, 337-396. [CrossRef]

13. Loehr, J.; Schwartz, T. The Making of a Corporate Athlete. Harv. Bus. Rev. 2001, 79, 120-128.

14. Ryan, R.M.; Frederick, C. On Energy, Personality, and Health: Subjective Vitality as a Dynamic Reflection of Well-Being. J. Personal. 1997, 65, 529-565. [CrossRef]

15. Baker, R.; Coenen, P.; Howie, E.; Lee, J.; Williamson, A.; Straker, L. A Detailed Description of the Short-Term Musculoskeletal and Cognitive Effects of Prolonged Standing for Office Computer Work. Ergonomics 2018, 61, 877-890. [CrossRef] 
16. Shirom, A. Feeling Vigorous at Work? The Construct of Vigor and the Study of Positive Affect in Organizations. In Emotional and Physiological Processes and Positive Intervention Strategies; Emerald Group Publishing Limited: Bingley, UK, 2004; Volume 3, pp. 135-164. ISBN 978-0-7623-1057-9.

17. Both-Nwabuwe, J.M.C.; Dijkstra, M.T.M.; Beersma, B. Sweeping the Floor or Putting a Man on the Moon: How to Define and Measure Meaningful Work. Front. Psychol. 2017, 8, 1658. [CrossRef]

18. Yang, M.; Fry, L.W. The Role of Spiritual Leadership in Reducing Healthcare Worker Burnout. J. Manag. Spiritual. Relig. 2018, 15, 305-324. [CrossRef]

19. Barnes, C.M.; Miller, J.A.; Bostock, S. Helping Employees Sleep Well: Effects of Cognitive Behavioral Therapy for Insomnia on Work Outcomes. J. Appl. Psychol. 2017, 102, 104-113. [CrossRef]

20. Ellingson, L.D.; Kuffel, A.E.; Vack, N.J.; Cook, D.B. Active and Sedentary Behaviors Influence Feelings of Energy and Fatigue in Women. Med. Sci. Sports Exerc. 2014, 46, 192-200. [CrossRef]

21. Prasad, M.; Wahlqvist, P.; Shikiar, R.; Shih, Y.-C.T. A Review of Self-Report Instruments Measuring Health-Related Work Productivity: A Patient-Reported Outcomes Perspective. Pharm. 2004, 22, 225-244. [CrossRef]

22. Niessen, C.; Sonnentag, S.; Sach, F. Thriving at Work-A Diary Study. J. Organ. Behav. 2012, 33, 468-487. [CrossRef]

23. Fredrickson, B.L. The Role of Positive Emotions in Positive Psychology: The Broaden-and-Build Theory of Positive Emotions. Am. Psychol. 2001, 56, 218-226. [CrossRef] [PubMed]

24. Allen, T.D.; Kiburz, K.M. Trait Mindfulness and Work-Family Balance among Working Parents: The Mediating Effects of Vitality and Sleep Quality. J. Vocat. Behav. 2012, 80, 372-379. [CrossRef]

25. Brown, K.W.; Ryan, R.M. The Benefits of Being Present: Mindfulness and Its Role in Psychological Well-Being. J. Personal. Soc. Psychol. 2003, 84, 822-848. [CrossRef]

26. Canby, N.K.; Cameron, I.M.; Calhoun, A.T.; Buchanan, G.M. A Brief Mindfulness Intervention for Healthy College Students and Its Effects on Psychological Distress, Self-Control, Meta-Mood, and Subjective Vitality. Mindfulness 2015, 6, 1071-1081. [CrossRef]

27. Sahin, S.; Özcan, N.A.; Babal, R.A. The Mediating Role of Thriving: Mindfulness and Contextual Performance among Turkish Nurses. J. Nurs. Manag. 2020, 28, 175-184. [CrossRef]

28. Zohar, D.; Marshall, I. Spiritual Intelligence: The Ultimate Intelligence; Bloomsbury Publishing: London, UK, 2000; ISBN 978-0-74753644-4.

29. Loehr, J.; Schwartz, T. The Power of Full Engagement: Managing Energy, Not Time, Is the Key to High Performance and Renewal; The Free Press: New York, NY, USA, 2003.

30. Spreitzer, G. Psychological Empowerment in the Workplace: Dimensions, Measurement, and Validation. Acad. Manag. J. 1995, 38, 1442-1465. [CrossRef]

31. Kim, E.S.; Strecher, V.J.; Ryff, C.D. Purpose in Life and Use of Preventive Health Care Services. Proc. Natl. Acad. Sci. USA 2014, 111, 16331-16336. [CrossRef]

32. Fawcett, S.E.; Brau, J.C.; Rhoads, G.K.; Whitlark, D.; Fawcett, A.M. Spirituality and Organizational Culture: Cultivating the ABCs of an Inspiring Workplace. Int. J. Public Adm. 2008, 31, 420-438. [CrossRef]

33. Hobfoll, S.E.; Shirom, A. Conservation of Resources Theory: Applications to Stress and Management in the Workplace. In Handbook of Organization Behavior; Dekker: New York, NY, USA, 2000; Volume 2, pp. 57-81.

34. Hoppe, A.; Toker, S.; Schachler, V.; Ziegler, M. The Effect of Change in Supervisor Support and Job Control on Change in Vigor: Differential Relationships for Immigrant and Native Employees in Israel: Supervisor Support, Job Control, and Vigor. J. Organiz. Behav. 2017, 38, 391-414. [CrossRef]

35. Wefald, A.J.; Smith, M.R.; Gopalan, N.; Downey, R.G. Workplace Vigor as a Distinct Positive Organizational Behavior Construct: Evaluating the Construct Validity of the Shirom-Melamed Vigor Measure (SMVM). Empl. Respons. Rights J. 2017, 29, 197-220. [CrossRef]

36. Adil, M.S.; Awais, A. Effects of Leader-Member Exchange, Interpersonal Relationship, Individual Feeling of Energy and Creative Work Involvement towards Turnover Intention: A Path Analysis Using Structural Equation Modeling. Asian Acad. Manag. J. 2016, 21, 99-133. [CrossRef]

37. Armon, G.; Shirom, A. The Across-Time Associations of the Five-Factor Model of Personality with Vigor and Its Facets Using the Bifactor Model. J. Personal. Assess. 2011, 93, 618-627. [CrossRef]

38. Cai, Y.; Song, Y.; Xiao, X.; Shi, W. The Effect of Social Capital on Tacit Knowledge-Sharing Intention: The Mediating Role of Employee Vigor. SAGE Open 2020, 10, 2158244020945722. [CrossRef]

39. Brewster, C.; Houldsworth, E.; Sparrow, P.; Vernon, G. International Human Resource Management, 4th ed.; Chartered Institute of Personnel and Development: London, UK, 2016; ISBN 978-1-84398-375-0.

40. Cooper, C.L.; Leiter, M.P. The Routledge Companion to Wellbeing at Work; Taylor \& Francis: Abingdon, UK, 2017; ISBN 978-1-31735372-0.

41. Tummers, L.; Steijn, B.; Nevicka, B.; Heerema, M. The Effects of Leadership and Job Autonomy on Vitality: Survey and Experimental Evidence. Rev. Public Pers. Adm. 2018, 38, 355-377. [CrossRef] [PubMed]

42. Gosselin, E.; Lemyre, L.; Corneil, W. Presenteeism and Absenteeism: Differentiated Understanding of Related Phenomena. J. Occup. Health Psychol. 2013, 18, 75-86. [CrossRef]

43. Bunderson, J.S.; Thompson, J.A. The Call of the Wild: Zookeepers, Callings, and the Double-Edged Sword of Deeply Meaningful Work. Adm. Sci. Q. 2009, 54, 32-57. [CrossRef] 
44. Walker, S.N.; Richter Sechrist, K.; Pender, N.J. The Health-Promoting Lifestyle Profile: Development and Psychometric Characteristics. Nurs. Res. 1987, 36, 76-81. [CrossRef]

45. Cole, M.S.; Bruch, H.; Vogel, B. Energy at Work: A Measurement Validation and Linkage to Unit Effectiveness: Productive Energy Measure. J. Organ. Behav. 2012, 33, 445-467. [CrossRef]

46. Donald, I.; Taylor, P.; Johnson, S.; Cooper, C.; Cartwright, S.; Robertson, S. Work Environments, Stress, and Productivity: An Examination Using ASSET. Int. J. Stress Manag. 2005, 12, 409-423. [CrossRef]

47. Jacobs, P.A.; Tytherleigh, M.Y.; Webb, C.; Cooper, C.L. Predictors of Work Performance among Higher Education Employees: An Examination Using the ASSET Model of Stress. Int. J. Stress Manag. 2007, 14, 199-210. [CrossRef]

48. Strijk, J.E.; Proper, K.I.; van Mechelen, W.; van der Beek, A.J. Effectiveness of a Worksite Lifestyle Intervention on Vitality, Work Engagement, Productivity, and Sick Leave: Results of a Randomized Controlled Trial. Scand. J. Work. Environ. Health 2013, 39 , 66-75. [CrossRef]

49. Faragher, E.B.; Cooper, C.L.; Cartwright, S. A Shortened Stress Evaluation Tool (ASSET). Stress Health 2004, 20, 189-201. [CrossRef]

50. Jain, A.; Giga, S.; Cooper, C. Stress, Health and Well-Being: The Mediating Role of Employee and Organizational Commitment. Int. J. Environ. Res. Public Health 2013, 10, 4907-4924. [CrossRef] [PubMed]

51. Arbuckle, J.L. Amos 6.0 User's Guide; SPSS Inc.: Chicago, IL, USA, 2005.

52. Good, D.J.; Lyddy, C.J.; Glomb, T.M.; Bono, J.E.; Brown, K.W.; Duffy, M.K.; Baer, R.A.; Brewer, J.A.; Lazar, S.W. Contemplating Mindfulness at Work: An Integrative Review. J. Manag. 2016, 42, 114-142. [CrossRef]

53. Kirag, N.; Ocaktan, E.M. Analysis of Health Promoting Lifestyle Behaviors and Associated Factors among Nurses at a University Hospital in Turkey. Saudi Med. J. 2013, 34, 1062-1067.

54. Schwartz, T.; McCarthy, C. Manage Your Energy, Not Your Time. Harv. Bus. Rev. 2007, 10, 1-10.

55. Boonyasiriwat, W.; Srisuwannatat, P.; Puttaravuttiporn, V. Are You Working Vigorously? Adaptation and Validation of the Thai Version of Shirom-Melamed Vigor Scale. J. Pac. Rim Psychol. 2017, 11, e8. [CrossRef] 